\title{
Power losses prediction in poly-v belt transmissions: application to front engine accessory drives.
}

\author{
Manin L. \\ Université de Lyon, CNRS, INSA-Lyon, LaMCoS UMR5259, F-69621, France \\ Lorenzon C. \\ Hutchinson transmission, Rue des Martyrs, 37304 Joué-Lès-Tours, France.
}

Liang $\mathbf{X}$.

Jiangsu sheng, Haimen, 20dong, 105. Postalcode:226100, China.

\begin{abstract}
This paper presents a method that permit to estimate a map of the power losses for any multi-pulley poly-v belt transmission. First, the work identifies and models the power losses in a simple two pulleys poly-v belt transmission, it focuses on the belt losses due to: the rubber hysteretic behavior, and the pulley-belt slip. The model developed is general so that it can be applied to any belt transmission. Finally, the developed model is extended to simulate the power losses of a multi pulley transmission such as a front engine accessory drives.
\end{abstract}

\section{INTRODUCTION}

The reduction of power losses is more than ever a big challenge for the car manufacturers. The work presented in this paper aims at participating to this effort by developing a method that permits to estimate a map of the power losses for any multi-pulley poly- $v$ belt transmission as used in automotive car engine. Although the amount of power losses that can be saved in a belt transmission is low compared to that of a car engine, it is a gain on the overall efficiency and it contributes to improve it.

The literature concerning power losses of belt transmission is relatively poor. It is mainly Gerbert (1) that had developed an advanced theory on this topic, but only for V and flat belts. Some experimental works $(2,3)$ give general trends on the v-belt performance regarding their efficiency versus the transmitted torque, the rotation speed and also the belt initial tension. Concerning poly- $v$ belts, the manufacturers are starting to communicate on this topic and some research studies are being conducted. Some experimental studies were done on the analysis of the pulley-belt slip (4) and the pulleybelt friction coefficient identification (5). The model developed in this paper is based on the theory developed in (1) for flat and V-belt and it is adapted to the case of poly-v belt.

At first, the work identifies and models the power losses in a simple two pulleys poly-v belt transmission. The transmission is operating at steady conditions. The paper focuses on the losses associated to the belt. These are of two main types, internal and external: energy loss due to the rubber hysteretic behavior, and energy loss due to pulley-belt slip. The first type is encountered for the bending, compression, stretching and shear strains of the belt. The second occurs on the pulleys that transmit power since implicitly some pulley-belt relative slip takes place. The belt hysteresis power losses are estimated by 
considering the imaginary part of the complex elasticity modulus of the belt rubber and also the different strains corresponding to the belt bending and compression. The belt shearing and stretching hysteresis losses are not considered in this work as for thin belt like poly-v belt the corresponding strains are very small. The complex modulus of the belt rubber is identified experimentally and is modeled by a linear function of the belt strain rate. The geometry, kinematic and dynamic parameters are considered as input of our model, they are provided by a previous calculation which is not developed here.

The third part is concerned with the transposition of the developed model to simulate the power losses of a multi pulley transmission such as a front engine accessory drive (Fig. 1). The distribution of each type of power losses is predicted and permits to draw a map of the power losses. It is shown that the dominant losses are due to pulley-belt-slip, belt bending and compression hysteresis.

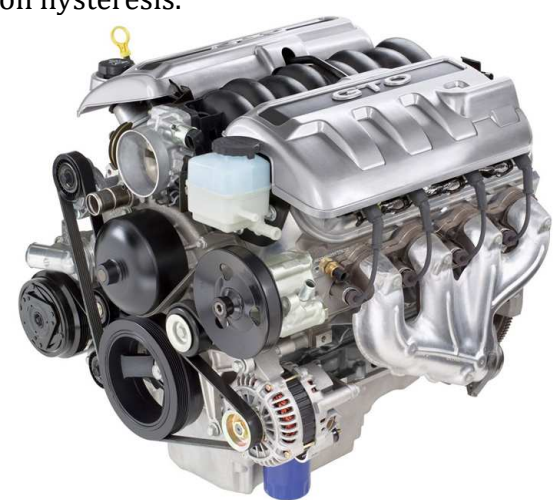

Figure 1- Car engine and its front end accessory drive (FEAD) belt transmission.

\section{MODELING BELT POWER LOSSES}

As illustrated in figure 1, two pulley/belt contact situations exist: the contact can take place on the back or on the ribs. For a standard belt transmission system, there are one driver pulley (here crankshaft pulley) and several driven pulleys. The power loss exists in the place where the belt and the pulleys are in contact. For a flat belt, the power losses can be divided mainly into five forms which are showed in the following table 1 . But in this work, the object is a poly-v belt for which another power loss has to be considered, it is the flank compression power loss for the ribs.

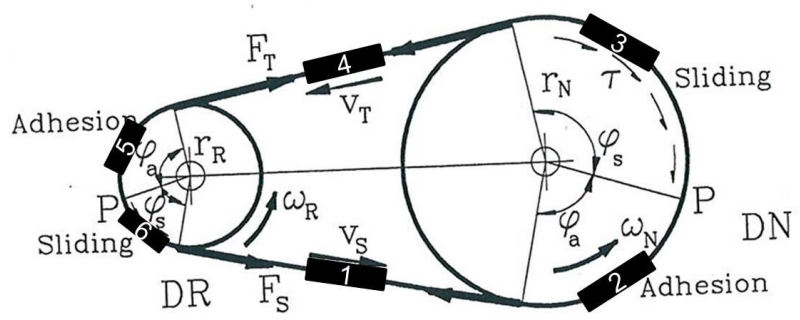

(a)

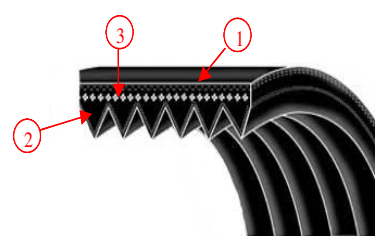

(b)

Figure 2: (a) Two pulleys transmission, subdivision of the belt into parts, (b) Poly-v belt, (1) back, (2) v-ribs, (3) cable

The locations of the power losses are defined on a basic belt transmission system with two pulleys which is illustrated in figure 2 . The contact arc of the pulley can be divided 
into two parts, the sliding arc and the adhesion arc. In the sliding arc, some creep occurs and there is a relative motion between the belt and the pulley. All the variables which are defined in the figures 2 and 3 are then used in the whole paper. The belt is divided into 6 parts which are each addressed by some specific power loss types. The table 2 indicates the type of power loss in each part.

\begin{tabular}{|c|c|c|c|}
\hline Loss & \multirow{2}{*}{ Schematic } & Belt parts & Energy loss forms \\
\hline \multirow[t]{2}{*}{ Bending } & & 1,4 & $\begin{array}{l}\text { Vibration tension } \\
\text { (dynamic) }\end{array}$ \\
\hline & & \multirow{4}{*}{3,6} & Bending \\
\hline \multirow{3}{*}{$\begin{array}{l}\text { Radial } \\
\text { Compression }\end{array}$} & \multirow{3}{*}{$T_{1}>^{T_{\theta}}+\frac{t}{444}$} & & Compression \\
\hline & & & Stretching \\
\hline & & & slip \\
\hline \multirow[t]{2}{*}{ Stretching } & \multirow{2}{*}{$\overbrace{T_{1}}^{\Delta T} \overbrace{1}^{T_{2}}$} & \multirow{5}{*}{2,5} & Bending \\
\hline & & & Compression \\
\hline \multirow{2}{*}{ Shear } & \multirow{2}{*}{$\begin{array}{l}\text { Belt } \\
\text { Element }\end{array}$} & & Stretching \\
\hline & & & \multirow[t]{2}{*}{ Shear } \\
\hline slip & $\delta \mathrm{I} \rightarrow \mid$ & & \\
\hline
\end{tabular}

Table 1: Power losses with belt concerns Table 2: Belt parts and associated power losses.

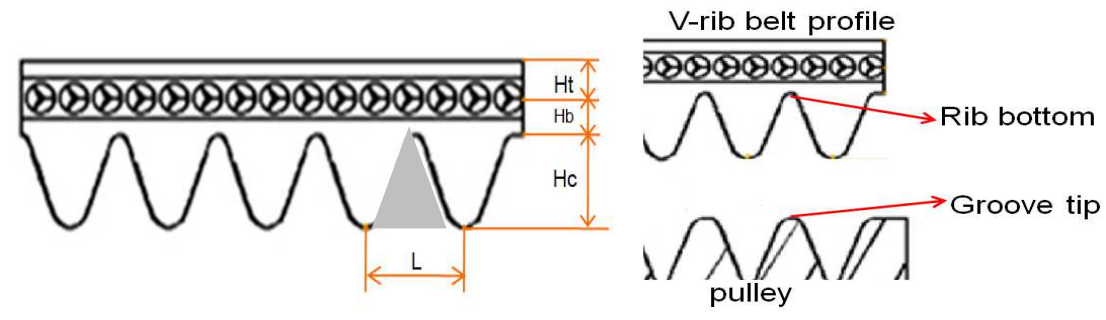

Figure 3: poly-v belt and pulley profile.

It should be noted that the rubber in the three parts (top, bottom, rib) of the belt is not a priori the same. Therefore, when calculating the power loss of the belt, it is necessary to consider individually the three parts in terms of material characteristics.

\subsection{Internal losses}

Some hypotheses are made in this research:

- The poly-v belt profile is simplified as represented in figure 5-b,

- $\quad$ The belt is only compressed by the flank pressure (wedge load, no bottom load), or the back side pressure

\subsubsection{Hysteresis losses, general theory}

In belt mechanics, a common way to describe the rubber belt hysteresis is to define a complex modulus $\mathrm{E}^{*}$ composed of a real part the elastic modulus $\mathrm{E}^{\prime}$ and an imaginary part the loss modulus E" (Fig 4):

$$
\mathrm{E}^{*}=\mathrm{E}^{\prime}+\mathrm{iE}
$$

Where $E^{\prime} \approx E=$ elastic modulus and $E^{\prime \prime}=$ loss modulus (hysteresis). 


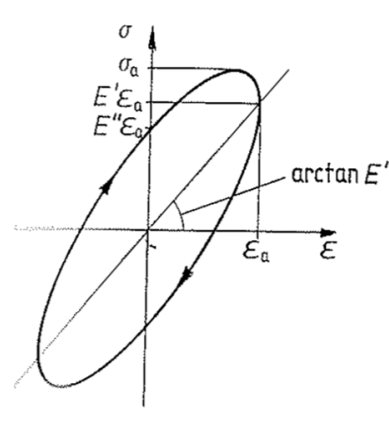

(a)

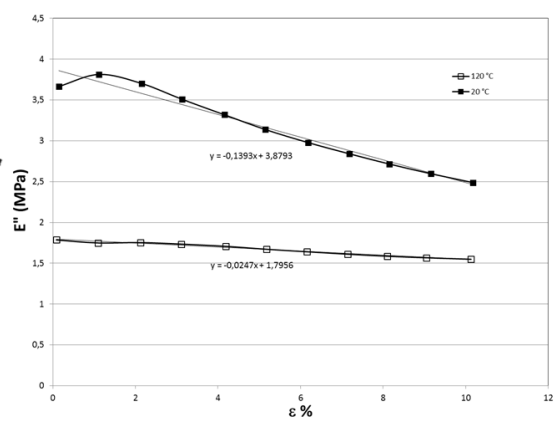

(b)

Figure 4: (a) Hysteresis loop, (b) Experimental determination of E" from DMA test.

When loading a piece of elastomer sinusoidally, the hysteresis loop in a stress-strain diagram is usually assumed to be an ellipse as represented in figure 4, the loop area is associated with the energy loss per volume $\left(\mathrm{J} / \mathrm{m}^{3}\right)$ which can be expressed as:

$$
\mathrm{W}_{\mathrm{h}}=\pi \cdot \mathrm{E}^{\prime \prime} \cdot \epsilon_{\mathrm{a}}^{2}
$$

Where $\pi$ is the circumference ratio. One can notice here that $W_{h}$ is proportional to the square of the strain amplitude $\varepsilon_{\mathrm{a}}{ }^{2}$, however several previous works (1) have shown experimentally that the energy loss is proportional both to $\varepsilon$ and $\varepsilon^{2}$, and therefore $\mathrm{W}_{\mathrm{h}}$ can also be expressed as:

$$
\mathrm{W}_{\mathrm{h}}=\sigma_{\mathrm{h}} \cdot \epsilon+\mathrm{E}_{\mathrm{h}} \cdot \epsilon^{2}
$$

where, $\sigma_{\mathrm{h}}$ and $\mathrm{E}_{\mathrm{h}}$ represent the material properties. They are two constants whose values have to be found by some experiments. Mostly experimental data of E" are available rather than data on $\sigma_{\mathrm{h}}$ and $\mathrm{E}_{\mathrm{h}}$, which are proposed here. However, they are related since $\epsilon=2 \epsilon_{\mathrm{a}}$ gives

And then

$$
\mathrm{W}_{\mathrm{h}}=\pi \cdot \mathrm{E}^{\prime \prime} \cdot \epsilon_{\mathrm{a}}^{2}=\sigma_{\mathrm{h}} \cdot \epsilon+\mathrm{E}_{\mathrm{h}} \cdot \epsilon^{2}
$$

$$
\mathrm{E}^{\prime \prime}=\frac{2 \sigma_{\mathrm{h}}}{\pi \epsilon_{\mathrm{a}}}+\frac{4 \mathrm{E}_{\mathrm{h}}}{\pi}
$$

This relationship indicates that E" is not constant but decreases with increasing amplitude, this is considered in the following but with a slightly different equation.

According to the previously developed hysteresis loss method, the relation between the loss modulus and the strain amplitude is given by the equation (5). But the numerous experiments that have been done by Hutchinson on a DMA with rubber samples have shown (Fig 4-b) that E" decreases with the strain amplitude. It can be estimated with the linear relation:

$$
\mathrm{E}^{\prime \prime}=\mathrm{a} \cdot \epsilon_{\mathrm{a}}+\mathrm{b}
$$

where, $\mathrm{a}$ and $\mathrm{b}$ are found by experiments. Thus, for calculating the power losses about the rubber of a poly-v belt, we should at first know these two coefficients, then the power loss per volume is given by:

$$
\mathrm{W}_{\mathrm{h}}=\pi \cdot \mathrm{E}^{\prime \prime} \cdot \epsilon_{\mathrm{a}}{ }^{2}=\pi\left(\mathrm{a} \cdot \epsilon_{\mathrm{a}}+\mathrm{b}\right) \epsilon_{\mathrm{a}}{ }^{2},\left(\mathrm{~W} / \mathrm{m}^{3}\right)
$$


This function is the basis used in the calculation for all the types of power loss in this work. It can be noted that these two coefficients are largely influenced by the temperature. Another point is that three layers of rubber compose the belt, therefore a and $b$ are different for these three layers. In the developed modeling, $a$ and $b$ are vectors $\left(a=\left[a_{1} a_{2}\right.\right.$ $\left.\left.a_{3}\right], b=\left[\begin{array}{lll}b_{1} & b_{2} & b_{3}\end{array}\right]\right)$ which represent the values of the top, the middle and the rib rubber layers. Then the key point to calculate the power loss is to find the strain amplitude $\epsilon_{\mathrm{a}}$ for every type of power loss (Eq. 7). Once the strain amplitude $\epsilon_{a}$ is determined, it is introduced in the equation 9 , we have the energy loss per volume Wh.

$$
\mathrm{W}_{\mathrm{h}}=\pi \cdot \mathrm{E}^{\prime \prime} \cdot \epsilon_{\mathrm{a}}{ }^{2}=\pi\left(\mathrm{a}_{\mathrm{i}} \epsilon_{\mathrm{a}}+\mathrm{b}_{\mathrm{i}}\right) \epsilon_{\mathrm{a}}{ }^{2}
$$

Where $\mathrm{i}$ is from 1 to 3 , then Wh is multiplied with the belt section area $\mathrm{S}$, we have the energy loss per unit length.

$$
\mathrm{W}_{\mathrm{h}(?)}=\pi \cdot \mathrm{E}^{\prime \prime} \cdot \epsilon_{\mathrm{a}}{ }^{2} \cdot \mathrm{S}
$$

Then, the power loss equals the energy loss per unit length multiplied with the belt speed $\left(\mathrm{V}=\mathrm{R}_{j} \omega_{j}\right)$, where $\mathrm{R}_{\mathrm{j}}$ is the pitch radius of a pulley $\mathrm{j}$ and $\omega_{j}$ is the rotation speed. The belt speed is considered constant as the study considers steady state operating conditions.

$$
P_{?}=W_{h(?)} \cdot R \cdot \omega=\pi \cdot E^{\prime \prime} \cdot \epsilon_{a}{ }^{2} \cdot S \cdot R \omega
$$

Where the ? stands for any type of strain (bending, compression). So, in the calculation process for all types of hysteresis power loss, the first objective is to find the strain amplitude $\epsilon_{\mathrm{a}}$.

\subsubsection{Bending losses}

Bending losses take place when a belt element enters a contact region, i.e. on a pulley. It depends on the level of strain and there it is directly related to the pulley radius.

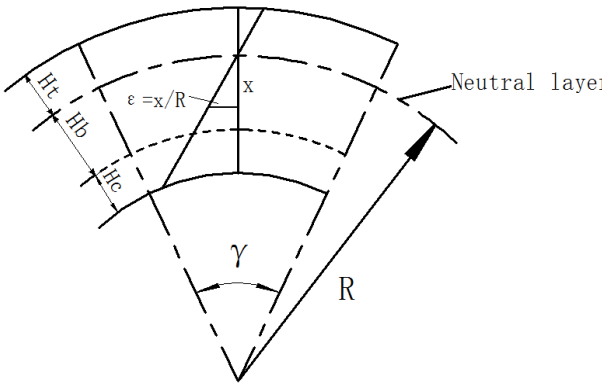

(a)

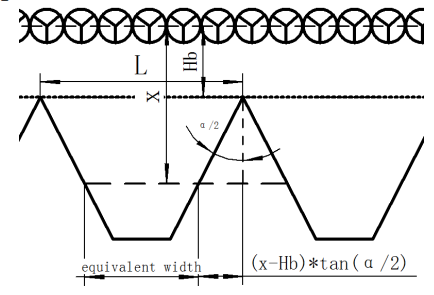

(b)

Figure 5: (a) Bending of a belt element around a pulley of radius $R$, (b) detailed geometry of poly-v belt profile

The method developed here is inspired form a published work on flat and v-belts (1) and it is transposed to the case of multi-ribbed belts. Bending losses are generated each time a cross section of the belt is bent around a pulley of pitch radius $\mathrm{R}$ and then unbent when exiting the contact region. According to the Fig 5(a), at a distance $\mathrm{x}$ from the cord layer (neutral layer) the strain amplitude is given by:

$$
\epsilon_{\mathrm{a}}=\frac{|(\mathrm{R} \mp \mathrm{x}) * \gamma-\mathrm{R} \gamma|}{\mathrm{R} \gamma}=\mathrm{x} / \mathrm{R}
$$


where $(\mathrm{R}-\mathrm{x})$ is for the strain in the $\mathrm{H}_{\mathrm{b}}$ or $\mathrm{H}_{\mathrm{c}}$ part and $(\mathrm{R}+\mathrm{x})$ in the $\mathrm{H}_{\mathrm{t}}$ part. Then combining the equations (7) and (11) and doing the integration over the belt cross section permits determining the total bending energy loss per unit length in the layer $\mathrm{H}_{\mathrm{i}}$ :

$$
\mathrm{W}_{\mathrm{h} \_\mathrm{b} \_\mathrm{i}}=\int_{0}^{\mathrm{Hi}} \pi\left(\mathrm{a}_{\mathrm{i}} \frac{\mathrm{x}}{\mathrm{R}}+\mathrm{b}_{\mathrm{i}}\right)\left(\frac{\mathrm{x}}{\mathrm{R}}\right)^{2} \mathrm{Bidx}
$$

where $\quad B$ is the belt width

$\mathrm{H}_{\mathrm{i}}$ is the thickness of the rubber layer $\mathrm{i}$.

In the rib part $\left(\mathrm{H}_{\mathrm{c}}\right)$, the belt width is not constant since there is no material between two ribs and this empty part cannot be taken into account in the calculation. Thus, an equivalent width is defined according to the simplified profile in figure 5(b) we can find that, in the rib part $\mathrm{H}_{c}$, the equivalent belt width can be expressed by:

$$
B-2\left(X-H_{b}\right) \tan \left(\frac{\alpha}{2}\right) \cdot n
$$

(131)Where $\mathrm{n}$ is the number of ribs of the belt considered.

In the general case, the power loss due to the bending on the pulley $j$ of radius $R_{j}$ is:

$$
\mathrm{P}_{h_{-} b}^{j}=\sum_{i} \mathrm{~W}_{\mathrm{hb}_{-} \mathrm{i}} \cdot R_{j} \cdot \omega_{j}
$$

For a series of $n$ pulleys whose radius are $R_{1}, R_{2}, R_{n} \ldots$, then the total power loss is

$$
P_{h_{-} b}^{t o t}=\sum_{j} \mathrm{P}_{h \_b}^{j}
$$

\subsubsection{Compression losses}

Compression losses are generated during the loading loop when the belt is compressed in the groove and then released.

\subsubsection{Flank compression losses}

The v-ribbed belt can be considered as a flat belt plus the ribs. Both of the two parts are compressed by the flank force $\mathrm{P}_{\mathrm{f}}$ (directly or indirectly) as is illustrated in the figure 6, so one must calculate the power loss individually for these two parts.

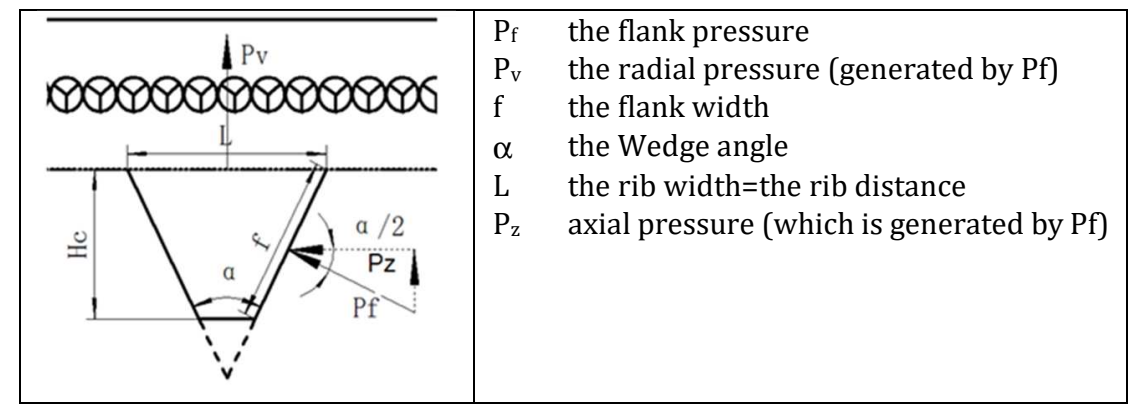

Figure 6: Simplified V-rib belt profile and rib flank compression pressure $\mathrm{P}_{\mathrm{f}}$ The belt is only compressed by the pulley on the flank surfaces of the ribs, and this pressure is $\mathrm{P}_{\mathrm{f}}$. Due to this pressure, the flat belt part is compressed by a vertical pressure $P_{v}$. The rib is compressed by an axial pressure $P_{z}$ and a vertical pressure $P_{v}$. But the influence of the $P_{v}$ to the rib is too small and is neglected. Both the $P_{v}$ and the $P_{z}$ pressures are calculated from the flank pressure $\mathrm{P}_{\mathrm{f}}$ by considering the rib geometry. 
The power loss of flank compression is only found on the ribs. The axial pressure $\mathrm{P}_{\mathrm{z}}$ causes a strain $\epsilon_{\mathrm{z}}=\frac{\mathrm{P}_{\mathrm{z}}}{\mathrm{E}_{\mathrm{z}}}$, thereby the energy loss per unit length:

$$
\mathrm{W}_{\mathrm{h}_{-} \mathrm{fc}}=\left[\pi\left(\mathrm{a}_{3} \frac{\mathrm{P}_{\mathrm{z}}}{\mathrm{E}_{\mathrm{z}}}+\mathrm{b}_{3}\right)\left(\frac{\mathrm{P}_{\mathrm{z}}}{\mathrm{E}_{\mathrm{z}}}\right)^{2}\right] \cdot \delta \cdot \mathrm{B} \cdot \mathrm{H}_{\mathrm{c}}
$$

Where $E_{z}$ is the rib axial stiffness, it is also the stiffness of the rubber. Its value is the E' (eq. 1). In fact, the E' is not a constant and the relation between the E' and the strain amplitude cannot be presented by an existing function. So Hutchinson has tested the rubber of the rib with a strain amplitude from 0 to $10 \%$, and get the average value of E'. According to the rib geometry, $\mathrm{P}_{\mathrm{z}}$ can be expressed by:

$$
\mathrm{P}_{\mathrm{z}}=\mathrm{P}_{f} \cdot \cos \frac{\alpha}{2}
$$

Where $P_{f}$ is the flank pressure and $\alpha$ the rib angle. The coefficient $\delta$ indicates the proportion of the rubber material in the rib part. It is determined by the rib profile and it is given by:

$$
\delta=\left[\mathrm{L}-\mathrm{H}_{\mathrm{c}} \cdot \tan (\alpha / 2)\right] / \mathrm{L}
$$

So when the belt is loaded by Pf, the power loss is:

$$
\Delta \mathrm{P}_{\mathrm{h}_{\mathrm{f}} \mathrm{fc}}=\left[\pi\left(\mathrm{a}_{3} \frac{\mathrm{P}_{\mathrm{z}}}{\mathrm{E}_{\mathrm{z}}}+\mathrm{b}_{3}\right)\left(\frac{\mathrm{P}_{\mathrm{z}}}{\mathrm{E}_{\mathrm{z}}}\right)^{2}\right] * \delta \mathrm{BH}_{\mathrm{c}} * \mathrm{R} \omega
$$

\subsubsection{Radial compression losses}

As it is illustrated in figure 6, when the belt is lying inside, the belt is under a radial compression $\mathrm{P}_{\mathrm{v}}$ which is generated by the flank pressure $\mathrm{P}_{\mathrm{f}}$. It assumes that the cord layer takes the most belt tension. So it is obviously that the material, which is between the cord layer and the rib (middle layer), is under the effect of radial compression, the thickness of this part is $\mathrm{H}_{\mathrm{b}}$. However, when the belt is lying outside, it is the top layer of the belt that is under radial compression, its thickness is $\mathrm{H}_{\mathrm{t}}$.

When the belt is lying inside the radial strain is given by $\mathrm{P}_{\mathrm{v}} / \mathrm{K}_{\mathrm{b}}$, with $\mathrm{K}_{\mathrm{b}}$ the radial stiffness. The power loss is then obtained by:

$$
\Delta \mathrm{P}_{h_{-} r c}=\left[\pi\left(\mathrm{a}_{2} \frac{\mathrm{P}_{v}}{\mathrm{~K}_{\mathrm{b}}}+\mathrm{b}_{2}\right)\left(\frac{\mathrm{P}_{v}}{\mathrm{~K}_{\mathrm{b}}}\right)^{2}\right] \text { B. } \mathrm{H}_{\mathrm{b}} * \mathrm{R} \cdot \omega
$$

Among the outputs of the dynamic behavior simulation software, we have the flank pressure $\mathrm{P}_{\mathrm{f}}$, thus the radial pressure can be found by:

$$
\mathrm{P}_{\mathrm{v}}=\frac{2 \cdot \mathrm{P}_{f} \cdot \mathrm{H}_{c} \cdot \tan \frac{\alpha}{2}}{\mathrm{~L}}
$$

When the belt is lying outside:

$$
\Delta \mathrm{P}_{h_{-} r c}=\left[\pi\left(\mathrm{a}_{1} \frac{\mathrm{P}_{v}}{\mathrm{~K}_{\mathrm{b}_{-} \mathrm{Ht}}}+\mathrm{b}_{1}\right)\left(\frac{\mathrm{P}_{v}}{\mathrm{~K}_{\mathrm{b}_{-} \mathrm{Ht}}}\right)^{2}\right] \text { B. } \mathrm{H}_{\mathrm{t}} \cdot \mathrm{R} \cdot \omega
$$

where $\mathrm{K}_{\mathrm{b}_{\mathrm{H}} \mathrm{Ht}}$ is the radial stiffness of the top layer. The power loss is just for one pulley whose flank pressure is $P_{f}$. In the case of a multi pulley transmissions, a specific value is used for each pulley, and these values are taken from the dynamic simulation results. 


\subsection{External losses}

The external losses are due to the pulley/belt slip, the friction moment of the bearings and the hysteresis of the tensioner (hydraulic or mechanic). As previously mentioned, in this work we focus only on the energy losses that imply the belt i.e., here the pulley/belt slip losses.

\subsubsection{Pulley/belt slip}

The slip power loss $\left(\Delta \mathrm{P}_{s l}\right)$ takes place in the sliding arc (Fig. 2) due to the relative speed between the belt and the pulley. Let's consider a very small belt segment which is in the sliding arc: the friction force for this segment is $\mathrm{dF}$ and the sliding speed for this segment is $V_{\text {s. }}$ Calculating the integral (eq. 23) in the sliding arc, then the power loss for any pulley is given by:

$$
\Delta \mathrm{P}_{s l}=\int_{0}^{\varphi_{\mathrm{s}}} \mathrm{v}_{\mathrm{s}} * \mathrm{dF}
$$

At an arbitrary position in the sliding arc, the velocity of the belt and the pulley are:

$$
\begin{aligned}
& V_{b}=V\left(1+\epsilon_{a}\right) \\
& V_{p}=(R-x) \omega
\end{aligned}
$$

Where, $\quad \epsilon_{\mathrm{a}}=\mathrm{F} / \mathrm{C} \quad$ is the belt tensile strain

$\mathrm{x}=\mathrm{P}_{\mathrm{v}} /\left(\mathrm{R}^{*} \mathrm{~K}_{\mathrm{b}}\right) \quad$ is the radial compression distance

$$
\mathrm{V} \quad \text { is the belt velocity }
$$

For the driven pulley, the belt moves faster than the pulley, so the sliding speed is:

$$
V_{s}=V_{b}-V_{p}=V\left(1+\epsilon_{a}\right)-R \omega\left(1-\frac{x}{R}\right)
$$

By transforming the equation we get ( $\mathrm{x} / \mathrm{R}$ being very small):

$$
\frac{\mathrm{R} \omega}{\mathrm{V}}=\frac{1+\epsilon_{\mathrm{a}}}{1-\frac{\mathrm{x}}{\mathrm{R}}}-\frac{\mathrm{V}_{\mathrm{s}}}{\mathrm{V}\left(1-\frac{\mathrm{x}}{\mathrm{R}}\right)} \approx 1+\epsilon_{\mathrm{a}}+\frac{\mathrm{x}}{\mathrm{R}}-\frac{\mathrm{V}_{\mathrm{s}}}{\mathrm{V}}
$$

At the beginning of the sliding $\operatorname{arc}, \mathrm{V}_{\mathrm{s}}=0$, then the equation (26) is changed to:

$$
\begin{gathered}
\frac{R \omega}{V}=1+\epsilon_{s}+\frac{x_{s}}{R} \\
\frac{V_{s}}{V}=\epsilon_{a}-\epsilon_{s}+\frac{x-x_{s}}{R}
\end{gathered}
$$

Where, $\epsilon_{\mathrm{s}}=\mathrm{F}_{\mathrm{s}} / \mathrm{C} \quad$ is the belt strain at the beginning of the sliding arc $\mathrm{x}_{\mathrm{s}}=\mathrm{F}_{\mathrm{s}} /\left(\mathrm{R} * \mathrm{~K}_{\mathrm{b}}\right) \quad$ is the radial compression distance

Then:

$$
\mathrm{V}_{\mathrm{s}}=\mathrm{V}\left(1+\mathrm{C}_{*}\right) \frac{\mathrm{F}-\mathrm{F}_{\mathrm{s}}}{\mathrm{C}}
$$

Where, $\mathrm{c}_{*}=\frac{\mathrm{C}}{\mathrm{K}_{\mathrm{b}} \mathrm{R}^{2}}$

Finally, for the driven pulley, we have the slip power loss: 


$$
\Delta \mathrm{P}_{\mathrm{sl} \_\mathrm{N}}=\int_{0}^{\varphi_{\mathrm{s}}} \mathrm{V}_{\mathrm{s}} * \mathrm{dF}=\frac{\mathrm{V}\left(1+\mathrm{C}_{* \mathrm{~N}}\right)}{\mathrm{C}} \int_{\mathrm{F}_{\mathrm{S}}}^{\mathrm{F}_{\mathrm{T}}}\left(\mathrm{F}-\mathrm{F}_{\mathrm{S}}\right) \mathrm{dF}=\frac{\mathrm{V}\left(1+\mathrm{C}_{* \mathrm{~N}}\right)}{2 \mathrm{C}}\left(\mathrm{F}_{\mathrm{T}}-\mathrm{F}_{\mathrm{S}}\right)^{2}
$$

And for the driver pulley we have:

$$
\Delta \mathrm{P}_{\mathrm{Sl} \_\mathrm{R}}=\frac{\mathrm{V}\left(1+\mathrm{C}_{* \mathrm{R}}\right)}{2 \mathrm{C}}\left(\mathrm{F}_{\mathrm{T}}-\mathrm{F}_{\mathrm{S}}\right)^{2}
$$

Where $\quad \mathrm{C}=\mathrm{E} . \mathrm{A}$ is the belt longitudinal stiffness, and $\mathrm{C}_{* \mathrm{R}}=\frac{\mathrm{C}}{\mathrm{K}_{\mathrm{b}} \mathrm{R}_{\mathrm{R}}^{2}}, \mathrm{C}_{* \mathrm{~N}}=\frac{\mathrm{C}}{\mathrm{K}_{\mathrm{b}} \mathrm{R}_{\mathrm{N}}^{2}}$.

For the case of the belt lying outside, the formulations are the same, but the $\mathrm{K}_{\mathrm{b}}$ change into $\mathrm{K}_{\mathrm{b}_{\mathrm{h}} \mathrm{ht}}$. When applying the previous equation to a pulley which is in a multi-pulleys system, Ft is the seating tension and Fs is the unseating tension. For a system with several pulleys, the total power loss is then given by:

$$
\Delta \mathrm{P}_{s l}^{\text {tot }}=\Delta \mathrm{P}_{\text {sl_R1 }}+\Delta \mathrm{P}_{\text {sl_R2 }}+\cdots \cdots+\Delta \mathrm{P}_{\text {sl_Rn }}
$$

\subsubsection{Bearing losses}

The basic formula for the friction moment of a bearing is given by:

$$
\mathrm{M}=0.5 * \mu * \mathrm{P} * \mathrm{~d},(\mathrm{~N} . \mathrm{m})
$$

where, $\quad \mu$ is the friction coefficient depending on the bearing type $\mathrm{P}$ is the hubload of the bearing $(\mathrm{N})$ $\mathrm{d}$ is the bearing bore diameter $(\mathrm{m})$

Then, the bearing power loss is given by:

$$
\mathrm{P}=\mathrm{M} * \omega
$$

Where, $\omega$ is the rotation speed of the considered pulley with the unit of $\mathrm{rad} / \mathrm{s}$

\section{MULTI PULLEYS TRANSMISSION}

In this part, the developed model is applied to a typical FEAD transmission. A six pulley transmission is considered as shown in figure $7(\mathrm{a})$. The crankshaft pulley (1) rotates clockwise, all the pulleys have a fixed centre, and there is no tensioner. Only the pulleys $(2,4,5)$ have resistant torques applied. The details of the transmission are not given for confidentiality purpose. Identical bearings have been considered for the six pulleys. The dynamic quantities needed to estimate the power losses have been previously calculated apart and are used as input of our modelling. The loss modulus of the belt have been measured experimentally as in (2.1.1), and the belt stiffness also. The aim here is to show the distribution of the power losses on each pulley and for each type of losses (Fig 7(b)): belt hysteresis bending (PLB), flank and radial compression hysteresis (PLFC, PLRC), belt slip (PLSL) and bearing losses (PLBE).

The belt slip power loss occurs only on the pulleys with a resistant torque. The hysteresis bending losses are the largest with the smallest pulley radius, and re inversely proportional to the pulley radius. It is observed that the radial compression losses are almost zero and can be neglected. On the opposite, the flank compression losses represent an important part of the total power loss for the pulley contacting the belt on its ribs. The bearing power losses are the highest on the fastest pulley. 


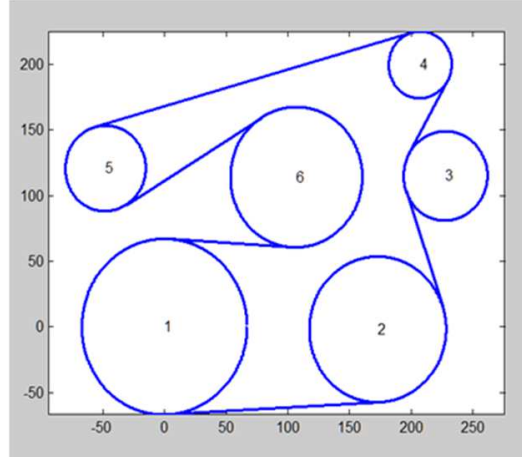

(a)

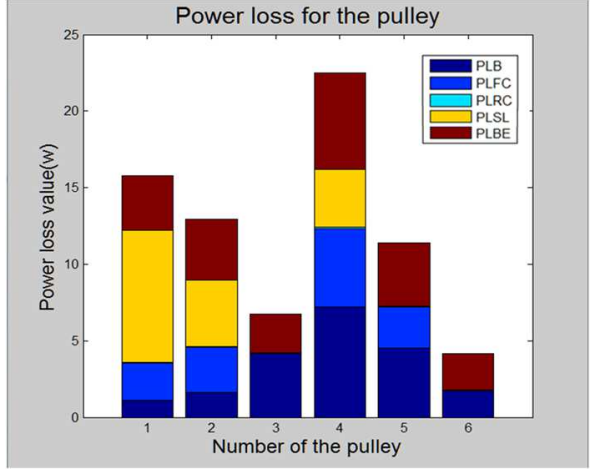

(b)

Figure 7: (a) 6 pulleys FEAD transmission, (b) distribution of the power losses

\section{CONCLUSION}

The work presented in this paper has established a model for predicting the power losses in a multi-pulley poly-v belt transmission. The belt internal losses due to hysteresis loss are considered and applied to the bending and the compression of the belt rubber. A general method for calculating these losses has been developed. The pulley belt/slip and the friction moments of the pulley bearings are taken into account, they constitute the external losses. The model needs some results of a dynamic behaviour simulation, it permits to draw a map of the power losses in the belt transmission. The next step will be the optimization of the transmission layout, setting tension, contact arcs in order to reduce these losses.

\section{REFERENCES}

[1] Gerbert, G., Traction belt mechanics, MVD, Chalmers, 1999, 600 p.

[2] Greenberg, S, De almedia, A., Technology assessment: energy-efficient belt transmissions .Energy and building .Vol22,p.245-253,1995.

[3] Energy loss and efficiency of power transmission belts ,advanced engineering research belt technical center springfield ,Missouri.

[4] Manin, L., Michon, G., Remond, Dufour, R. (2009), From transmission error measurement to Pulley-Belt slip determination in serpentine belt drives: influence of tensioner and belt characteristics, Mechanism and Machine Theory, 44-4, 813-821.

[5] Cepon, G., Manin, L., Boltezar, M. (2010), Experimental identification of the contact parameters between a V-ribbed belt and a pulley, Mechanism and Machine Theory, 45, 1424-1433, doi:10.1016/j.mechmachtheory.2010.05.006. 